\title{
Elevada diversidade genética interpopulacional em Oryza glumaepatula Steud. (Poaceae) avaliada com microssatélites
}

\author{
Cynthia Maria Silva ${ }^{1}$, Marines Marli Gniech Karasawa ${ }^{1}$, Roland Vencovsky ${ }^{1}$ \& Elizabeth Ann Veasey ${ }^{1,2}$
}

Biota Neotropica v7 (n2) - http://www.biotaneotropica.org.br/v7n2/pt/abstract?article +bn04607022007

Recebido em 10/11/06

Versão reformulada recebida em 24/06/07

Publicado em 21/07//07

${ }^{1}$ Departamento de Genética, ESALQ, Universidade de São Paulo - USP,

Av. Pádua Dias, 11, CP 83, CEP 13400-970, Piracicaba, SP

${ }^{2}$ Autor para correspondência: Elizabeth Ann Veasey,e-mail: eaveasey@esalq.usp.br,

http://www.genetica.esalq.usp.br

\begin{abstract}
Silva, C.M., Karasawa, M.M.G., Vencovsky, R. \& Veasey, E.A. High interpopulational genetic diversity of Oryza glumaepatula Steud. (Poaceae) assessed with microsatellites. Biota Neotrop. May/Aug 2007 vol. 7 , no. 2. http://www.biotaneotropica.org.br/v7n2/pt/abstract?article+bn04607022007. ISSN 1676-0603.

Microsatellite markers were used to characterize the genetic diversity within and among seven natural populations of Oryza glumaepaula. Six of these populations originated from the hydrographic basin of the Amazon and one from Rio Paraguay in the Pantanal Matogrossense. Using seven microsatellite loci, the following intrapopulation genetic diversity parameters were estimated on average: 1.98 alleles per locus, $56.2 \%$ polymorphic loci, $H_{o}=0.026$ and $H_{e}=0.241$. High interpopulational differentiation was noticed by examining Wright's fixation index and Slatkin's divergence parameter ( $F_{S T}=0.715$ and $R_{S T}=0.595$, respectively), as well as a high level of total inbreeding $\left(F_{I T}=0.963\right)$, greatly influenced by the mating system $\left(F_{I S}=0.858\right)$. No population was in Hardy-Weinberg equilibrium, due to the prevailing autogamic mating behavior, as also indicated by the average apparent outcrossing rate observed: $\bar{t}_{a}=0.055$. Consequently, among populations gene flow was practically absent, which has contributed to the high interpopulational genetic divergence. In general, very low or null outcrossing rates were found in the Amazonian populations. However, population PG-3 from Rio Paraguay, originated from Pantanal Matogrossense, showed a higher outcrossing rate (13.2\%), indicating a mixed mating system with the predominance of self-fertilization. Since intrapopulation diversity was low, results indicate that sampling a large number of populations is the most appropriate strategy for the ex situ conservation of this species. For in situ conservation, taking in consideration the allelic richness, the following populations are indicated as priority: PG-3, TA-3, SO-17, and NE-7, from the hydrographic basins of the rivers Paraguay, Tapajos, Solimoes and Negro, respectively.
\end{abstract}

Keywords: genetic diversity, genetic structure, Oryza glumaepatula, microsatellites, mating system, populations.

\section{Resumo}

Silva, C.M., Karasawa, M.M.G., Vencovsky, R. \& Veasey, E.A. Elevada diversidade genética em populações de Oryza glumaepatula Steud. (Poaceae) avaliada com microssatélites. Biota Neotrop. May/Aug 2007 vol. 7 , no. 2. http://www.biotaneotropica.org.br/v7n2/pt/abstract?article+bn04607022007. ISSN 1676-0603.

Marcadores microssatélites foram usados para caracterizar a diversidade genética entre e dentro de sete populações naturais de Oryza glumaepaula. Seis dessas populações são originárias da bacia hidrográfica da Amazônia e uma do rio Paraguai no Pantanal Matogrossense. Utilizando sete locos de microssatélites, observou-se diversidade genética intrapopulacional média de 1,98 alelos por loco, 56,2\% de locos polimórficos, $H=0,026$ e $H_{e}=0,241$. Elevada diferenciação interpopulacional foi observada pelo índice de fixação de Wright e pelo parâmetro de divergência de Slatkin $\left(F_{S T}=0,715\right.$ e $R_{S T}=0,595$, respectivamente), bem como elevado nível de endogamia total $\left(F_{I T}=0,963\right)$, em grande parte influenciada pelo sistema reprodutivo $\left(F_{I S}=0,858\right)$. Verificou-se que nenhuma população estava em equilíbrio de Hardy-Weinberg, devido ao predomínio da autofertilização, o que também pôde ser verificado pela taxa média aparente de cruzamentos: $\bar{t}_{a}=0,055$. Consequentemente, o fluxo gênico entre populações foi praticamente nulo o que contribuiu para o elevado nível de divergência interpopulacional. De modo geral, as taxas de cruzamento foram muito baixas ou nulas nas populações da Amazônia. Entretanto, a população PG-3 do Rio Paraguai, originária do Pantanal Matogrossense, apresentou taxa de cruzamento mais elevada (13,2\%), indicando sistema reprodutivo misto com predomínio de autogamia. Como a diversidade intrapopulacional foi baixa, os resultados indicam que a amostragem de elevado número de populações é a estratégia mais adequada para a conservação ex situ desta espécie. Para a conservação in situ, com base na riqueza alélica, recomenda-se como prioridade as populações PG-3, TA-3, SO-17 e NE-7, originárias das bacias hidrográficas dos Rios Paraguai, Tapajós, Solimões e Negro, respectivamente.

Palavras-chave: diversidade genética, estrutura genética, Oryza glumaepatula, microssatélites, sistema reprodutivo, populações. 


\section{Introdução}

O processo evolutivo e de domesticação do arroz fez surgir inúmeros tipos divergentes geneticamente adaptados às mais variadas condições agro-ecológicas, fazendo com que o arroz seja um dos cereais mais cultivados e consumidos no mundo. Pertencente ao gênero Oryza, família Poaceae, o arroz apresenta apenas duas espécies cultivadas e 21 espécies selvagens (Khush 1997).

No Brasil são encontradas quatro espécies selvagens, que também são distribuídas pela América Central e outros países da América do Sul. São elas $O$. glumaepatula Steud., que é diplóide $(2 \mathrm{n}=24$, genoma $\mathrm{A}^{\mathrm{gp}} \mathrm{A}^{\mathrm{gp}}$ ), e O. alta, O. grandiglumis e O. latifolia, que são tetraplóides ( $2 n=48$, genoma CCDD) (Ando 1998). Essas espécies retêm suas características selvagens em áreas altamente isoladas ainda livres da pressão humana, na floresta tropical Amazônica e áreas alagadas do Centro-oeste brasileiro chamado Pantanal Matogrossense (Buso et al. 1998). As espécies selvagens, principalmente $O$. glumaepatula, podem ser utilizadas como um rico reservatório gênico (Rangel 1998). Em longo prazo, os seguintes aspectos podem ser explorados: identificação de novos genes de resistência às doenças, ampliação da base genética e obtenção de cultivares flotantes. A transferência da adaptabilidade das espécies selvagens às águas profundas para as variedades cultivadas pode trazer grandes benefícios aos caboclos da Amazônia (Rangel 1998). Por outro lado, para que se possa melhorar as estratégias de manejo e conservação dessas espécies, é necessário conhecer a estrutura e a diversidade genética de suas populações (Carthew 1993; Brown \& Moran 1981). Só assim será possível preservar ao máximo os recursos genéticos existentes, que incluem toda a variação herdável dentro de populações de uma mesma espécie (Moran \& Hopper 1987).

Os microssatélites ou SSR (simple sequence repeats) têm sido altamente indicados e usados nos estudos de genética de populações de plantas nativas devido à sua reprodutibilidade (Ferreira \& Grattapaglia 1998), por serem considerados variantes geneticamente neutros e por serem geneticamente mais informativos para esse tipo de estudo (Brondani et al. 2002). Os locos SSR possuem expressão co-dominante, são altamente multialélicos e apresentam segregação mendeliana. O uso de marcadores moleculares de alto desempenho permite uma amostragem muito eficiente do genoma e a estimação da divergência genética, variabilidade e discriminação entre genótipos (Grattapaglia 2001).

Os microssatélites têm sido utilizados para estudos de diversidade, estrutura genética e genética da conservação em $O$. rufipogon Griff. (Gao et al. 2000a, 2002a,b; Gao 2004), espécie de arroz selvagem de origem asiática e reconhecida como ancestral da espécie cultivada O. sativa L. (Khush 1997). Este marcador vem sendo também desenvolvido para outras espécies de arroz selvagem, como
O. officinalis Wall ex Watt., O. granulata Nees et Arn. ex Watt., $O$. latifolia Desv., O. minuta J.S. Presl. ex C.B. Presl., O. australiensis Domin e O. ridleyi Hook. (Ishii \& McCouch 2000; Gao et al. 2000b, 2005; Gao 2005; Zhou et al. 2003). Para a espécie O. glumaepatula, podem ser citados, em especial, os trabalhos realizados por Brondani et al. $(2001,2002)$, que apresentam iniciadores selecionados e testados para esta espécie, Brondani et al. (2005) e Karasawa et al. (2007) que obtiveram estimativas da estrutura genética e do sistema reprodutivo em populações brasileiras de $O$. glumaepatula.

Este estudo teve como objetivos avaliar a diversidade genética e parâmetros de estrutura genética, utilizando marcadores microssatélites, em sete populações de $O$. glumaepatula, não contempladas em estudos anteriores, originárias da Amazônia e do Pantanal Matogrossense, visando fornecer maiores subsídios para a conservação genética dessas populações e espécie.

\section{Material e Métodos}

\section{Material avaliado}

Foram avaliadas sete populações de Oryza glumaepatula (Tabela 1), originárias da Bacia Hidrográfica da Amazônia, mais especificamente do Rio Tapajós (TA-2 e TA-3), Rio Negro (NE-7) e Rio Solimões (SO-2, SO-17 e SO-21) e da Bacia Hidrográfica do Rio Paraguai (PG-3). Essas populações fazem parte do Banco de Germoplasma de arroz silvestre do Departamento de Genética da ESALQ/USP, Piracicaba, SP.

Inicialmente foi formado um bulk de 40 sementes por população, coletando-se uma semente de cada família (planta-mãe), exceto as populações SO-2, TA-3 e NE-7 que tinham menos que 40 famílias, de onde foram tomadas duas sementes por família para formar o bulk (Tabela 1). As sementes, previamente tratadas com hipoclorito de sódio a $1 \%$ por 5 minutos, foram colocadas em caixas Gerbox com papel de filtro umedecido em água destilada e mantidas em germinador a $27^{\circ} \pm 5^{\circ} \mathrm{C}$ no escuro. As sementes recém germinadas foram plantadas em vasos e mantidas em casa-de-vegetação. Estas foram regadas diariamente por sistema automático de aspersão. Foram inicialmente colocados para germinar um total de 280 sementes, mas em função de falhas na germinação e de um problema ocorrido no sistema de irrigação na casa-de-vegetação, puderam ser efetivamente avaliados apenas 117 indivíduos, variando de 12 a 24 indivíduos por população (Tabela 1).

\section{Análise de microssatélites}

Para a extração de DNA, folhas recém-expandidas de cada planta individual foram maceradas em nitrogênio líquido e submetidas à metodologia proposta por Hoisinton et al. (1994) modificada por

Tabela 1. Descrição das populações de Oryza glumaepatula: número de indivíduos avaliados (N), número de famílias amostradas (F) e origem (bacia hidrográfica, rio e/ou lago de ocorrência e coordenada geográfica).

Table 1. List of Oryza glumaepatula populations: number of individuals evaluated (N), number of families sampled (F) and origin (hydrographic basin, river and/or lake of origin and geographic location).

\begin{tabular}{ccccccc}
\hline População & N & F & Bacia Hidrográfica & Rio & Lago & Coordenada Geográfica \\
\hline SO-2 & 24 & 27 & Solimões & - & Caldeirão & $03^{\circ} 16^{\prime} \mathrm{S}-60^{\circ} 13^{\prime} \mathrm{W}$ \\
SO-17 & 18 & 40 & Solimões & - & Coari & $-1^{\prime}$ \\
SO-21 & 18 & 40 & Solimões & - & Mamiá & $04^{\circ} 15^{\prime} \mathrm{S}-63^{\circ} 03^{\prime} \mathrm{W}$ \\
PG-3 & 18 & 40 & Paraguai & Corumbá & - & $18^{\circ} 59^{\prime} \mathrm{S}-57^{\circ} 37^{\prime} \mathrm{W}$ \\
TA-2 & 13 & 22 & Tapajós & Tapajós & - & - \\
TA-3 & 12 & 22 & Tapajós & Tapajós & - & - \\
NE-7 & 14 & 40 & Negro & Negro & - & $1^{\circ} 24^{\prime} \mathrm{S}-61^{\circ} 59^{\prime} \mathrm{W}$ \\
\hline
\end{tabular}

${ }^{1}$ Dados de coordenadas geográficas não disponíveis. 
Karasawa (2005), baseada em tampão CTAB 10\%. O DNA extraído foi quantificado em gel de poliacrilamida a $4 \%$, tomando-se por referencial DNA padrão com amplitude de variação de 10, 20, 40, 80 e $160 \mathrm{ng}$, corado com nitrato de prata (Bassam et al. 1991).

Sete iniciadores desenvolvidos por Brondani et al. (2001) foram selecionados (OG 22, OG 26, OG 29, OG 36, OG 39, OG 42 e OG 63) para amplificação dos locos em estudo, apresentando diferentes temperaturas ótimas de anelamento testadas por Karasawa (2005) (Tabela 2). Em cada reação de PCR foram utilizados $30 \mathrm{ng}$ de DNA genômico em $12 \mu \mathrm{L}$ de volume, o qual continha $0,3 \mu \mathrm{M}$ de cada primer, $0,25 \mathrm{mM}$ de cada dNTP, 1,5 mM de $\mathrm{MgCl}_{2}, 10 \mathrm{mM}$ de Tris- $\mathrm{HCl}$ e 0,6 unidades da enzima Taq DNA polimerase (Gibco BRL). Utilizou-se o seguinte programa para as reações de PCR (reações em cadeia da polimerase) no termociclador da marca Primus 96: um ciclo de $94{ }^{\circ} \mathrm{C}$ por 4 minutos para desnaturação inicial; 30 ciclos de: $94{ }^{\circ} \mathrm{C}$ por 1 minuto; temperatura de anelamento de cada iniciador $\left(54,56\right.$ e $58^{\circ} \mathrm{C}$ ) por 1 minuto e $72{ }^{\circ} \mathrm{C}$ por 1 minuto para elongação; finalizando com um ciclo de $72{ }^{\circ} \mathrm{C}$ por 5 minutos para a extensão final.

Os produtos da amplificação foram separados em gel de poliacrilamida a $6 \%$ sob voltagem de 80 volts por 15 minutos e 120 volts por duas horas (dependendo do iniciador) em tampão TBE 1X. Foram utilizados marcadores padrão com peso molecular de $10 \mathrm{pb}$ e de $100 \mathrm{pb}$ (Gibco BRL). Depois de amplificado e separado, o material foi corado com nitrato de prata, seguindo o mesmo procedimento da coloração do gel de quantificação, e fotodocumentado (Figura 1).

\section{Análise estatística}

Para a análise estatística foram calculadas as frequiências alélicas a partir da interpretação do padrão de bandas nos géis. Esses dados foram submetidos ao teste de probabilidade para aderência ao equilíbrio de Hardy-Weinberg pelo método convencional de Monte Carlo, utilizando o programa TFPGA (Miller 1997). Estimaram-se os parâmetros de diversidade genética, tais como número médio de alelos por loco $(A)$, porcentagem de locos polimórficos $(P)$, heterozigosidade média observada $\left(H_{o}\right)$, diversidade gênica $\left(H_{e}\right)$ e índice de fixação de Wright $(f)$, bem como as estimativas das estatíticas F de Wright $\left(F_{I S}, F_{S T}, F_{I I}\right)$, e do parâmetro $R_{S T}$ (Slatkin 1995), que fornece uma medida da diversidade genética entre populações naturais assumindo a evolução dos locos SSR pelo modelo de ilhas, através do programa GDA (Lewis \& Zaykin 2000). A estimativa do número de migrantes foi realizada utilizando a seguinte equação: $N_{m}=1 / 4\left(1 /\left(F_{S T}\right.\right.$ ou $\left.R_{S T}\right)$. Um dendrograma foi obtido a partir de distâncias genéticas de Nei (1978), utilizando o método aglomerativo UPGMA (Unweighted pair group method of arithmetic averages). As taxas de cruzamento aparente foram estimadas por população $\left[t_{a}=(1-f) /(1+f)\right]$ e para a média das populações $\left(\bar{t}_{a}=(1-\bar{f}) /(1+\bar{f})\right.$. A presença de alelos privados foi obtida pelo programa GDA (Lewis \& Zaykin 2000).
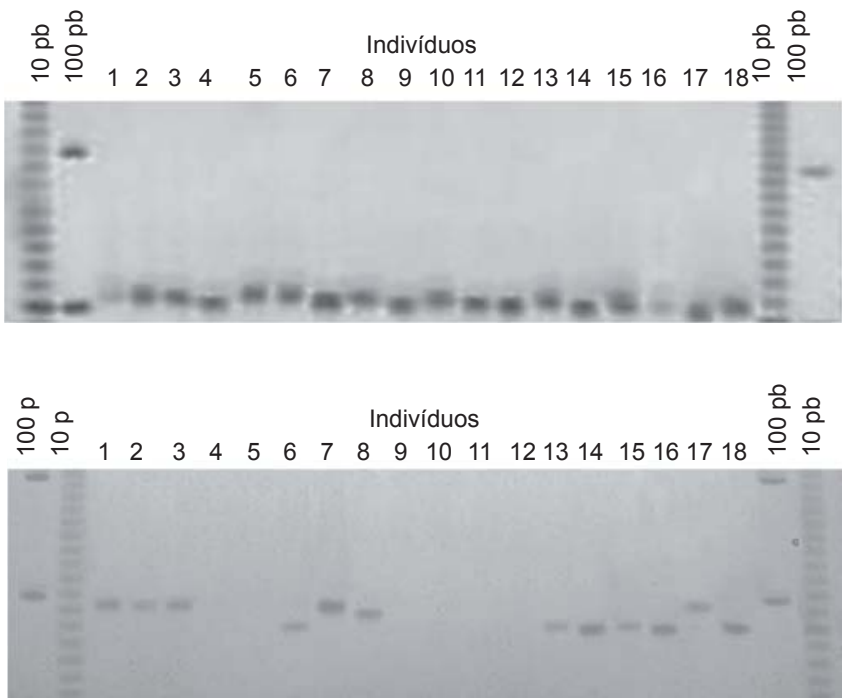

Figura 1. Gel de poliacrilamida $6 \%$, corado com nitrato de prata, para os iniciadores OG-29 (acima) e OG-36 (abaixo), e população SO-17.

Figure 1. Poliacrilamide gel (6\%), stained with silver nitrate, for primers OG-29 (above) and OG-36 (below), and population SO-17.

Tabela 2. Seqüências de iniciadores ${ }^{1}$ selecionados para Oryza glumaepatula com as temperaturas de anelamentos (TA), os tamanhos dos fragmentos (Pb), números de alelos por loco $(A)$, heterozigosidade observada $\left(\mathrm{H}_{\mathrm{o}}\right)$ e diversidade gênica $\left(\mathrm{H}_{\mathrm{e}}\right)$.

Table 2. Primer sequences developed for Oryza glumaepatula with the annealing temperatures (TA), size range ( $\mathrm{Pb})$, number of alleles per locus (A), observed heterozygosity $\left(\mathrm{H}_{\mathrm{o}}\right)$ and gene diversity $\left(\mathrm{H}_{\mathrm{e}}\right)$.

\begin{tabular}{|c|c|c|c|c|c|c|}
\hline Primers & Seqüência Forward/Reverse & TA $\left({ }^{\circ} \mathbf{C}\right)$ & $P b$ & $A$ & $\boldsymbol{H}_{o}$ & $\boldsymbol{H}_{e}$ \\
\hline OG 22 & $\begin{array}{l}\text { (F) GCCATCCATTCTTACCAG } \\
\text { (R) CACAGGTGTGGTGCTCA }\end{array}$ & 56 & $190-200$ & 3 & 0,0111 & 0,6032 \\
\hline OG 26 & $\begin{array}{l}\text { (F) CATGGTGCCGATTACGGT } \\
\text { (R) CATCTCCATCGCGGTCAT }\end{array}$ & 58 & $90-110$ & 4 & 0,0184 & 0,5821 \\
\hline OG 29 & $\begin{array}{l}\text { (F) GACCAGTTCACCATGCAG } \\
\text { (R) GAGTGAGGCAGCAAGACA }\end{array}$ & 56 & $85-125$ & 8 & 0,0187 & 0,7757 \\
\hline OG 36 & $\begin{array}{l}\text { (F) AACGTTCATCGGTTCTGG } \\
\text { (R) TGCTTGCCAGGTTATTCC }\end{array}$ & 56 & $160-195$ & 8 & 0,1429 & 0,8193 \\
\hline OG 39 & $\begin{array}{l}\text { (F) GCGTACTAGGCCATGATA } \\
\text { (R) TCCACGTAAGAACACTCG }\end{array}$ & 56 & $260-280$ & 4 & 0,0100 & 0,6951 \\
\hline OG 42 & $\begin{array}{l}\text { (F) TGCAGGCTCTGAGCTAC } \\
\text { (R) AGAACAGATCTTGCCGTC }\end{array}$ & 58 & $430-440$ & 3 & 0,0000 & 0,5226 \\
\hline OG 63 & $\begin{array}{l}\text { (F) CAGGGGACAAGCACATA } \\
\text { (R) TAGACGATGTCGAGAAGG }\end{array}$ & 54 & $130-155$ & 5 & 0,0000 & 0,7137 \\
\hline Média & - & - & - & 5 & 0,0287 & 0,6731 \\
\hline
\end{tabular}




\section{Resultados}

A partir dos sete locos utilizados foram amplificados 35 alelos em sete populações de $O$. glumaepatula, num total de 117 indivíduos (Tabela 3). Todos os locos apresentaram polimorfismo. O número de alelos por loco variou de três a oito, sendo a média de cinco alelos por loco (Tabela 2). Entretanto, este número mostrou considerável variação entre as populações (um a seis) (Tabela 3). O número médio de alelos por loco para as sete populações foi 1,98, variando em média de 1,14 a 3,00 alelos, sendo que a porcentagem média de locos polimórficos foi de 56,19\%, variando de 14,29 a 71,43\% (Tabela 4).

Baixos foram os valores de heterozigosidade observados em relação aos valores de heterozigosidade esperados em cada loco (Tabela 2) e nas sete populações (Tabela 4), indicando excesso de homozigotos. As populações apresentaram valores entre 0,000 e 0,077 (com média de 0,026 ) para heterozigosidade observada e entre 0,067 e 0,405 (com média de 0,241) para a diversidade gênica. As diferenças entre os dois índices de heterozigosidades das populações podem ser melhor avaliadas pelas estimativas dos índices de fixação intrapopulacional de Wright, que foram elevadas, variando de 0,767 a 1,000 (Tabela 4), exceto a população SO-2 cujo índice de fixação não pôde ser estimado por ter apresentado apenas um loco segregando. As taxas de cruzamento aparente estimadas apresentaram variações de 0 a 13,2\%. De modo geral, as populações da Amazônia apresentaram taxas de cruzamento muito baixas ou nulas, variando de 0 a 3,9\%. Por outro lado, a população PG-3 da bacia hidrográfica do Rio Paraguai, originária do Pantanal Matogrossense, apresentou taxa de cruzamento mais elevada $(13,1 \%)$, Considerando os dados relativos ao índice de fixação e à taxa média de cruzamento aparente (5,5\%) também é possível verificar a existência de predomínio de homozigotos e do sistema reprodutivo por autogamia nas populações avaliadas.

$\mathrm{O}$ teste de aderência ao equilíbrio de Hardy-Weinberg mostrou que ocorrem desvios significativos em todas as populações. O elevado coeficiente de endogamia total $\left(F_{I T}=0,963\right)$ detectado nas populações do estudo indica que o efeito preponderante foi gerado pelo sistema reprodutivo $\left(F_{I S}=0,858\right)$, o que contribuiu para a diferenciação intrapopulacional. O nível de subdivisão interpopulacional $\left(F_{S T}=0,715\right.$ e $\left.R_{S T}=0,595\right)$ também contribuiu para a endogamia total, mas em menor grau (Tabela 5). Por outro lado, a estimativa obtida para o número de migrantes, em cada geração, foi de $N_{m}=0,100$ e 0,170 , respectivamente para $F_{S T}$ e $R_{S T}$.

Tabela 3. Frequiências alélicas observadas em sete locos em sete populações de Oryza glumaepatula.

Table 3. Allele frequencies observed in seven loci within seven populations of Oryza glumaepatula.

\begin{tabular}{|c|c|c|c|c|c|c|c|c|c|}
\hline Loco & Alelo (pb) & SO-2 & SO-17 & SO-21 & PG-3 & NE-7 & TA-2 & TA-3 & Média \\
\hline \multirow[t]{3}{*}{ OG 22} & 190 & 1,000 & 0,200 & - & - & 0,464 & 0,100 & 0,455 & 0,370 \\
\hline & 195 & - & 0,133 & 0,937 & - & 0,536 & 0,900 & 0,545 & 0,509 \\
\hline & 200 & - & 0,667 & 0,063 & - & - & - & - & 0,122 \\
\hline \multirow[t]{4}{*}{ OG 26} & 90 & - & - & - & - & 0,071 & - & 0,250 & 0,046 \\
\hline & 95 & - & - & - & - & 0,393 & 0,500 & - & 0,128 \\
\hline & 100 & 1,000 & 1,000 & 1,000 & - & 0,536 & - & - & 0,505 \\
\hline & 110 & - & - & - & 1,000 & - & 0,500 & 0,750 & 0,321 \\
\hline \multirow[t]{8}{*}{ OG 29} & 85 & - & - & - & 0,300 & - & - & - & 0,043 \\
\hline & 90 & - & - & - & 0,050 & - & - & 0,167 & 0,031 \\
\hline & 95 & - & - & - & 0,100 & 0,929 & - & 0,333 & 0,195 \\
\hline & 100 & - & - & - & 0,300 & - & 0,923 & 0,333 & 0,222 \\
\hline & 105 & - & 0,556 & 0,813 & - & - & - & - & 0,195 \\
\hline & 110 & 1,000 & 0,444 & 0,125 & 0,200 & 0,071 & - & - & 0,263 \\
\hline & 120 & - & - & 0,063 & 0,050 & - & - & - & 0,016 \\
\hline & 125 & - & - & - & - & - & 0,077 & 0,167 & 0,035 \\
\hline \multirow[t]{8}{*}{ OG 36} & 160 & 0,354 & - & - & - & - & - & - & 0,051 \\
\hline & 165 & - & - & - & 0,031 & - & - & - & 0,004 \\
\hline & 170 & - & 0,333 & - & - & 0,462 & 0,182 & 0,167 & 0,163 \\
\hline & 175 & - & 0,167 & - & 0,063 & - & - & - & 0,033 \\
\hline & 180 & - & 0,083 & 0,900 & 0,781 & - & - & 0,167 & 0,276 \\
\hline & 185 & - & - & 0,100 & 0,125 & - & 0,818 & 0,667 & 0,244 \\
\hline & 190 & 0,646 & 0,417 & - & - & 0,077 & - & - & 0,163 \\
\hline & 195 & - & - & - & - & 0,462 & - & - & 0,066 \\
\hline \multirow[t]{4}{*}{ OG 39} & 260 & 1,000 & - & - & - & - & - & - & 0,143 \\
\hline & 270 & - & 1,000 & 0,615 & 0,077 & - & 1,000 & 1,000 & 0,527 \\
\hline & 275 & - & - & - & 0,038 & 1,000 & - & - & 0,148 \\
\hline & 280 & - & - & 0,385 & 0,885 & - & - & - & 0,181 \\
\hline \multirow[t]{3}{*}{ OG 42} & 430 & 1,000 & 0,889 & - & - & - & - & - & 0,315 \\
\hline & 435 & - & - & - & 1,000 & 1,000 & 1,000 & 1,000 & 0,667 \\
\hline & 440 & - & 0,111 & - & - & - & - & - & 0,019 \\
\hline \multirow[t]{5}{*}{ OG 63} & 130 & - & 1,000 & 1,000 & - & - & - & - & 0,400 \\
\hline & 135 & 1,000 & - & - & - & - & - & - & 0,200 \\
\hline & 140 & - & - & - & - & - & 1,000 & 0,167 & 0,233 \\
\hline & 145 & - & - & - & - & - & - & 0,417 & 0,083 \\
\hline & 155 & - & - & - & - & - & - & 0,417 & 0,083 \\
\hline
\end{tabular}


Tabela 4. Parâmetros de diversidade genética ${ }^{1}$ avaliados em sete populações de Oryza glumaepatula.

Table 4. Parameters of genetic diversity ${ }^{1}$ assessed in seven populations of Oryza glumaepatula.

\begin{tabular}{lccccccc}
\hline População & $\mathbf{N}$ & $\boldsymbol{A}$ & $\boldsymbol{P}$ & $\boldsymbol{H}_{o}$ & $\boldsymbol{H}_{e}$ & $\boldsymbol{F}$ \\
\hline PG-3 & 12,2 & 3,00 & 60,00 & 0,0679 & 0,2810 & 0,767 & 0,1319 \\
TA-3 & 11,9 & 2,29 & 71,43 & 0,0000 & 0,4055 & 1,000 \\
SO-17 & 16,1 & 2,00 & 57,14 & 0,0000 & 0,2766 & 1,000 \\
NE-7 & 13,8 & 2,00 & 66,67 & 0,0238 & 0,3031 & 0,924 & 0,0000 \\
SO-21 & 12,0 & 1,83 & 66,67 & 0,0000 & 0,1889 & 1,000 & 0,0395 \\
TA-2 & 10,7 & 1,57 & 57,14 & 0,0110 & 0,1670 & 0,936 & 0,0000 \\
SO-2 & 24,0 & 1,14 & 14,29 & 0,0774 & 0,0667 & - & - \\
Média & 14,4 & 1,98 & 56,19 & 0,0257 & 0,2412 & 0,8959 & 0,055 \\
\hline
\end{tabular}

${ }^{1} \mathrm{~N}$ - número médio de plântulas amostrados por loco; $A$ - número médio de alelos por loco; $P$ - porcentagem de locos polimórficos; $H_{o}$ - heterozigosidade média observada; $H_{e}$ - diversidade gênica; $f$ - índice de fixação de Wright e $t_{a}$ - taxa de cruzamento aparente.

Tabela 5. Estimativas das estatísticas $F$ de Wright e do parâmetro $R_{S T}$ (Slatkin 1995) em Oryza glumaepatula.

Table 5. Estimates of Wright's $F$ statistics and of the $R_{S T}$ parameter (Slatkin 1995) in Oryza glumaepatula.

\begin{tabular}{lrrrc}
\hline & $F_{I T}$ & $F_{I S}$ & $F_{S T}$ & $R_{S T}$ \\
\hline Para todos os locos & 0,963 & 0,858 & 0,715 & 0,5948 \\
Superior (IC 95\%)* & 0,993 & 0,962 & 0,836 & - \\
Inferior (IC 95\%) & 0,915 & 0,769 & 0,590 & - \\
\hline
\end{tabular}

*Intervalo de confiança de $95 \%$.

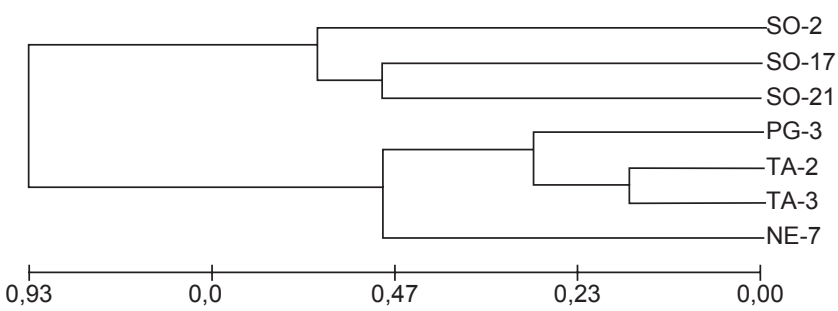

Figura 2. Dendrograma obtido pelo método UPGMA utilizando distâncias genéticas de Nei (1978) com sete locos de microssatélites em sete populações de Oryza glumaepatula.

Figure 2. Dendrogram obtained by the UPGMA method using Nei (1978) genetic distances with seven microsatellite loci in seven Oryza glumaepatula populations.

A análise de agrupamento (Figura 2) gerada com base nas distâncias genéticas de Nei (1978) mostrou a formação de dois grupos, um contendo as três populações da bacia do Rio Solimões e o outro contendo as demais populações das bacias dos Rios Negro, Tapajós e Paraguai. Observou-se maior proximidade entre as populações TA-2 e TA-3, ambas do Rio Tapajós, seguidas pela população PG-3 originária do Rio Paraguai. Por outro lado, verificou-se a ocorrência de certo distanciamento da população NE-7, do Rio Negro. O estudo do número de alelos privados indicou a sua existência em cinco das sete populações estudadas, sendo observados três alelos na população SO-2, dois na PG-3 e TA-3 e um alelo nas populações SO-17 e NE-7 (Figura 3).

\section{Discussão}

No presente estudo a análise de sete locos avaliados em sete populações (117 indivíduos) identificou 35 alelos, com média de cinco alelos por loco. Este número foi inferior aos obtidos por outros autores na mesma espécie. Karasawa et al. (2007), utilizando oito

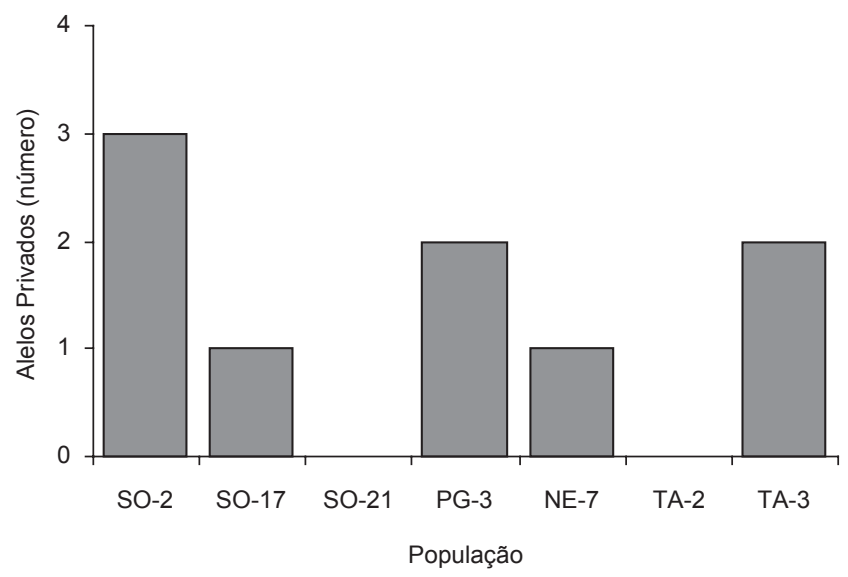

Figura 3. Frequiência de alelos privados em sete populações de Oryza glumaepatula.

Figure 3. Frequency of private alleles for seven Oryza glumaepatula populations.

locos de microssatélites, amplificaram 80 alelos em 11 populações de $O$. glumaepatula (total de 330 indivíduos), sendo a média de dez alelos por loco, enquanto Brondani et al. (2005) analisando 10 locos SSR obtiveram 103 alelos em 30 populações de O. glumaepatula (total de 440 indivíduos), uma média de 10,3 alelos por loco observado.

$\mathrm{O}$ número de alelos privados encontrados em cinco das sete populações (Figura 3), ficou assim distribuído: três alelos na população SO-2, dois na PG-3 e TA-3 e um alelo nas populações SO-17 e NE-7. Karasawa et al. (2007), estudando 11 populações com maior número de indivíduos amostrados por população (variando de 17 a 35) e utilizando oito locos de SSR, observaram alelos privados em nove populações, variando de 1,0 a 8,0 por população. Por outro lado, Brondani et al. (2005) analisando de três a 24 indivíduos em 30 populações de $O$. glumaepatula com dez locos de microssatélites, encontraram 29 alelos privados distribuídos em 12 das 30 populações. Possivelmente, o menor número de indivíduos amostrados no presente estudo tenha limitado a detecção de alelos privados. Entretanto, o número foi considerável se for levado em conta o número médio de alelos encontrados nas populações.

Os valores de heterozigosidade observados em cada loco (Tabela 2) e nas sete populações (Tabela 4) foram baixos quando comparados à diversidade gênica ou $H_{e}$, o que demonstra haver excesso de homozigotos. Portanto, indivíduos heterozigóticos são pouco comuns nessas populações. Buso et al. (1998), estudando quatro populações de 
O. glumaepatula do Brasil com auxílio de marcadores isoenzimáticos, verificaram que a heterozigosidade observada $\left(H_{0}\right)$ foi de 0,006 , em média, e a diversidade gênica $\left(H_{e}\right)$ foi de 0,062 . Valores mais elevados, semelhantes aos obtidos no presente estudo, para a heterozigosidade observada $\left(H_{0}\right)$ (média de 0,027$)$, foram obtidos por Brondani et al. (2005) para marcadores microssatélites, que é um marcador mais informativo, bem como valores mais elevados que Buso et al. (1998) para a diversidade gênica $\left(H_{e}=0,115\right)$. Por outro lado, Karasawa et al. (2007), também utilizando microssatélites, obtiveram índices médios mais elevados de $H_{0}=0,091$ e $H_{e}=0,393$. Acredita-se que este desvio seja decorrente, em parte, do maior número de indivíduos avaliados, que neste último estudo foi de 27,4 por população. Considerando-se o fato de se tratar de uma espécie com predomínio de autogamia, presume-se que a maior parte dos indivíduos da população sejam homozigóticos e que os heterozigóticos, bem como os alelos privados, estejam numa condição mais rara. Assim sendo, para que se tenha a oportunidade de capturá-los na amostragem seria necessário aumentar consideravelmente o tamanho da amostra.

As estimativas dos índices de fixação intrapopulacionais de Wright indicaram a existência de elevada taxa de endogamia em todas as populações, exceto a população SO-2 cujo índice de fixação não pôde ser estimado por ter apresentado apenas um loco segregando. Esses elevados índices de endogamia refletiram nas taxas de cruzamento aparente observadas. De modo geral, as populações da Amazônia apresentaram taxas de cruzamento muito baixas ou nulas. No entanto, a população PG-3 do Rio Paraguai, originária do Pantanal Matogrossense, apresentou taxa de cruzamento mais elevada $(\bar{t}=0,131)$, indicando sistema reprodutivo misto com predomínio de autogamia para esta população, o que concorda com as informações prévias obtidas por Karasawa et al. (2007) para as populações do Paraguai, sendo o valor médio obtido exatamente o mesmo. Entretanto, a taxa de cruzamento aparente média obtida $\left(\bar{t}_{a}=0,055\right)$ foi inferior às obtidas por Brondani et al. (2005), $\bar{t}=0,135$, e por Karasawa et al. (2007), $\bar{t}_{a}=0,143$, para $O$. glumaepatula. Acredita-se que esta menor estimativa obtida ocorreu, principalmente, pela maior proporção de populações amazônicas no presente estudo, enquanto Karasawa et al. (2007) e Brondani et al. (2005) amostraram também populações da região do pantanal e do cerrado brasileiro. Considerando-se as informações prévias de que estas praticam um maior nível de alogamia, é possível compreender o fato pelo qual a taxa de cruzamento média foi superior nos estudos anteriores.

As estimativas da aderência ao equilíbrio de Hardy-Weinberg mostram que as populações não se encontram em equilíbrio em seu habitat natural. Elevados valores para a endogamia intrapopulacional foram observados neste estudo $\left(F_{I S}=0,858\right)$, sendo que os níveis de subdivisão interpopulacional $\left(F_{S T}=0,715\right.$ e $\left.R_{S T}=0,595\right)$ foram também expressivos, contribuindo em menor grau para a endogamia total da espécie. Brondani et al. (2005) também observaram, com marcadores SSR, valores elevados para a diferenciação interpopulacional $\left(F_{S T}=0,847\right.$ e $\left.R_{S T}=0,901\right)$, sendo de 0,968 a endogamia total $\left(F_{I T}\right)$ e a endogamia intrapopulacional de $F_{I S}=0,794$. Já Karasawa et al. (2007) obtiveram valores menores para a diferenciação interpopulacional $\left(F_{S T}=0,491\right.$ e $\left.R_{S T}=0,608\right)$ em 11 populações de $O$. glumaepatula, sendo que as estimativas da endogamia total $\left(F_{I T}=0,888\right)$ foram consideradas decorrentes principalmente do sistema reprodutivo, em função da alta endogamia intrapopulacional observada $\left(F_{I S}=0,780\right)$.

A estimativa do número de migrantes por geração $\left(N_{m}=0,100 \mathrm{e}\right.$ 0,170 , respectivamente para $F_{S T}$ e $R_{S T}$ ) apresentou valores reduzidos, indicando que a troca de genes entre as populações avaliadas desta espécie praticamente inexiste. Considerando-se o índice obtido para dados de microssatélites $\left(R_{S T}\right)$, verificou-se que a estimativa deste estudo concorda com o valor obtido por Karasawa et al. (2007), que foi de 0,16 . Esta espécie se multiplica pela dispersão de plantas pela abscisão programada e flutuação rio abaixo, e pela dispersão de sementes nessas ilhas flutuantes, sendo que a dispersão de sementes em O. glumaepatula é mais importante que a dispersão do pólen (Akimoto et al., 1998). Mesmo assim, baixos valores de troca de genes foram observados para as populações avaliadas neste estudo.

Pela análise de agrupamento observou-se a formação de dois grupos, um contendo as três populações da bacia do Rio Solimões e o outro contendo as demais populações das bacias dos Rios Negro, Tapajós e Paraguai. Akimoto et al. (1998) também observaram a separação de duas populações do Rio Negro das demais populações do Rio Solimões e do Rio Jaú, sugerindo uma diferenciação geográfica entre bacias hidrográficas na Amazônia. Os motivos que teriam levado a esta diferenciação, segundo os autores, seriam: i) a ocorrência de deriva genética por afunilamento causado por extinções de populações, o que estaria ocorrendo em função da baixa germinação de sementes e sobrevivência de plântulas sob inundação, além dos baixos índices de dormência observados, confirmados por Veasey et al. (2004) no caso de populações originárias da Amazônia; e ii) a baixa oportunidade de hibridação com outras espécies, se comparado com populações asiáticas e africanas selvagens de $O$. rufipogon, que frequentemente se hibridizam com a espécie cultivada ( $O$. sativa).

Pelo dendrograma pode-se verificar que as populações se agruparam aproximadamente de acordo com as suas respectivas bacias hidrográficas, contrariando os resultados previamente obtidos por Karasawa et al. (2007). A população PG-3, originária da bacia hidrográfica do Rio Paraguai, em área do Pantanal Matogrossense, não foi classificada num grupo isolado das demais populações da Amazônia, como seria esperado pela maior distância geográfica e impossibilidade de haver fluxo gênico entre esta população e as da Amazônia, e pelas diferentes condições climáticas e ecológicas, o que também foi observado por Karasawa et al. (2007). No entanto, esta separação foi nítida quando foram utilizados marcadores isoenzimáticos (Veasey et al. 2008), tendo sido observadas freqüências alélicas diferenciadas em função dos dois biomas, com predominância de parte dos alelos no Pantanal e parte na Amazônia em dois locos isoenzimáticos.

A partir da caracterização das sete populações de $O$. glumaepatula, pôde-se verificar o elevado nível de diversidade genética interpopulacional, baixos níveis de heterozigosidade observada e elevados índices de endogamia em decorrência do sistema reprodutivo. $\mathrm{O}$ conhecimento da distribuição da variabilidade genética entre e dentro de populações naturais de $O$. glumaepatula é essencial para a adoção de estratégias visando à conservação deste germoplasma em condições ex situ e in situ e para seu uso potencial em cruzamentos interespecíficos em programas de melhoramento genético de arroz (Brondani et al. 2001, 2002).

Acredita-se que o uso de marcadores microssatélites promoveu suficiente precisão dos resultados, apesar do pequeno número amostrado de indivíduos, permitindo, assim, a definição de estratégias de conservação in situ e ex situ. A necessidade de coleta de sementes de um maior número de populações é uma das conclusões deste estudo para a conservação ex situ, principalmente considerando não apenas a maior divergência entre populações, mas também a variação observada nas taxas de cruzamento aparente entre populações. Já a riqueza alélica pode ser um critério a se considerar para a definição da conservação in situ dessas populações. Com base neste critério, para conservação in situ foram identificadas as populações PG-3, TA-3, SO-17 e NE-7, das bacias hidrográficas dos Rios Paraguai, Tapajós, Solimões e Negro, respectivamente, por apresentarem número maior de alelos e índices de diversidade gênica mais elevados, assegurando a preservação de maior diversidade intrapopulacional da espécie em estudo. 


\section{Agradecimentos}

Os autores agradecem ao Conselho Nacional de Desenvolvimento Científico e Tecnológico (CNPq) pelas bolsas concedidas e financiamento da pesquisa.

\section{Referências Bibliográficas}

AKIMOTO, M., SHIMAMOTO, Y. \& MORISHIMA, H. 1998. Population genetic structure of wild Oryza glumaepatula distributed in the Amazon flood area influenced by its life-history traits. Mol. Ecol. 7:1371-1381.

ANDO, A. 1998. Coletas de germoplasma de espécies de espécies selvagens e relativas ao gênero Oryza no Brasil, Paraguai e Argentina. In Encontro sobre Temas de Genética e Melhoramento, 15, Anais, ESALQ/USP, Piracicaba, p.22-26.

BASSAM, B.J., CAETANO-ANOLLES, G. \& GRESSHOFF, P.M. 1991. Fast and sensitive silver staining of DNA in polyacrylamide gels. Anal. Biochem. 196:80-83.

BRONDANI, C., BRONDANI, R.P.V., RANGEL, P.H.N. \& FERREIRA, M.E. 2001. Development and mapping of Oryza glumaepatula - derived microsatellite markers in the interspecific cross Oryza glumaepatula $\mathrm{x}$ Oryza sativa. Hereditas 134:59-71.

BRONDANI, C., RANGEL, P.H.N., BRONDANI, R.P.V. \& FERREIRA, M.E. 2002. QTL mapping and introgression of yield-related traits from Oryza glumaepatula to cultivated rice (Oryza sativa) using microsatellite markers. Theor. Appl. Genet. 104:1192-1203.

BRONDANI, R.P.V., ZUCCHI, M.I., BRONDANI, C., RANGEL, P.H.N., BORBA, T.C.O., RANGEL, P.N., MAGALHÃES, M.R. \& VENCOVSKY, R. 2005. Genetic structure of wild rice Oryza glumaepatula populations in three Brazilian biomes using microsatellite markers. Genética 125:115-123.

BROWN, A.H.D. \& MORAN, G.F. 1981. Isozymes and the genetic resources of forest trees. In Isozymes of North American Forest Insects (M.T. Conckle, ed.), U.S. Department Agriculture, Berkeley, p.1-10.

BUSO, G.S.C., RANGEL, P.H. \& FERREIRA, M.E. 1998. Analysis of genetic variability of South American wild rice populacions (Oryza glumaepatula) with isozymes and RAPD markers. Mol. Ecol. 7:107-117.

CARTHEW, S.M. 1993. Population genetic structure of Banksia spinulosa. Heredity, London.70 (6):566-573.

FERREIRA, M.E. \& GRATTAPAGLIA, D. 1998. Introdução ao uso de marcadores moleculares em análise genética. 2. ed. Embrapa-Cenargen, Brasília.

GAO, L.Z. 2004. Population structure and conservation genetics of wild rice Oryza rufipogon (Poaceae): a region-wide perspective from microsatellite variation. Mol. Ecol. 13:1009-1024.

GAO, L.Z. 2005. Microsatellite variation within and among populations of Oryza officinalis (Poaceae), an endangered wild rice from China. Mol. Ecol. 14:4287-4297.

GAO, L.Z., GE, S. \& HONG, D.Y. 2000a. Allozyme variation and population genetic structure of common wild rice Oryza rufipogon Griff. in China. Theor. Appl. Genet. 101:494-502.

GAO, L.Z., GE, S. \& HONG, D.Y. 2000b. Low levels of genetic diversity within population and high differentiation among populations of a wild rice, Oryza granulata Nees et. Arn. ex. Watt. from China. Int. J. Plant. Sci. 161:691-697.

GAO, L.Z., SCHAAL, B.A., ZHANG, C.H., JIA, J.Z. \& DONG, Y.S. 2002a. Assessment of population genetic structure in common wild rice Oryza rufipogon Griff. using microsatellite and allozyme markers. Theor. Appl. Genet. 106:173-180.

GAO, L.Z., GE, S. \& HONG, D.Y. 2002b. Allozyme variation and conservation genetics of common wild rice (Oryza rufipogon Griff.) in Yunnan, China. Euphytica 124:273-281.

GAO, L.Z., ZHANG, C.H. \& JIA, J.Z. 2005. Cross-species transferability of rice microsatellites in its wild relatives and the potential for conservation genetic studies. Genet. Resour. Crop. Evol. 52(7):931-940

GRATTAPAGLIA, D. 2001. Marcadores moleculares em espécies florestais: Eucalyptus como modelo. In Recursos genéticos e melhoramento - plantas (L.L. Nass, A.C.C. Valois, I.S. Melo \& M.C. Valadares-Inglis, eds.). Fundação MT, Rondonópolis, p.967-993.

HOISINGTON, D., KHAIRALLAH, M. \& GONZALES-DE-LEON, D. 1994. Laboratory protocols CIMMYT, $2^{\text {nd }}$ ed. Applied Molecular Genetics Laboratory, CIMMYT, El Batan, México.

ISHII, T. \& McCOUCH, S.R. 2000. Microsatellites and microsynteny in the chloroplast genomes of Oryza and eight other Gramineae species. Theor. Appl. Genet. 100(8):1257-1266.

KARASAWA, M.M.G. 2005. Análise da estrutura genética de populações e sistema reprodutivo de Oryza glumaepatula por meio de microssatélites. Tese de doutorado. Escola Superior de Agricultura "Luiz de Queiroz", Universidade de São Paulo, Piracicaba.

KARASAWA, M.A.G., VENCOVSKY, R., SILVA, C.M., ZUCCHI, M.I., OLIVEIRA, G.C.X. \& VEASEY, E.A. 2007. Genetic structure of Brazilian Oryza glumaepatula Steud. (Poaceae) populations studied with microsatellite markers. Gen Mol Biol 30(2):400-410.

KHUSH, G.S. 1997. Origin, dispersal, cultivation and variation of rice. Plant Mol. Biol. 35:25-34.

LEWIS, P.O. \& ZAYKIN, D. 2000. Genetic Data Analysis: computer program for the analysis of allelic data. Version 1.0 (d15). http://alleyn.eeb. uconn.edu/gda.

MILLER, M. P. 1997. Tools for Population Genetic Analyses (TFPGA) 1.3: a windows program for the analysis of allozyme and molecular population genetic data. http://www.public.asu.edu.

MORAN, G.F. \& HOPPER, S.D. 1987. Conservation of the genetic resources of rare and widespread eucalypts in remnant vegetation. In Nature conservation: The role of remnants native vegetation (D.A. Saunders, G.W. Arnold, A.A. Burbidge \& A.J.M. Hopkins, eds). Beatty, Surrey, p.151-162.

NEI, M. 1978. Estimation of average heterozygosity and genetic distance from a small number of individuals. Genetics 89:583-590.

RANGEL, P.H.N. 1998. Origem e evolução do arroz. In I Curso Internacional de Melhoramento Genético de Arroz. Goiânia, 16-27 março, 1998.

SLATKIN, M. 1995. A measure of population subdivision based on microsatellite allele frequencies. Genetics 139:457-462.

VEASEY, E.A., KARASAWA, M.G., SANTOS, P.P., ROSA, M.S., MAMANI, E. \& OLIVEIRA, G.C. 2004. Variation in the loss of seed dormancy during after-ripening of wild and cultivated rice species. Ann. Bot. 94:875-882.

VEASEY, E.A., CARDIN, D.C., SILVA, R.M., BRESSAN, E.A. \& VENCOVSKY, R. 2008. Assessing the genetic structure of Oryza glumaepatula populations with isozyme markers. Braz. Arch. Biol. Technol., no prelo.

ZHOU, H.F., ZHONG, W.X. \& GE, S. 2003. Microsatellite analysis of genetic diversity and population genetic structure of a wild rice (Oryza rufipogon Griff.) in China. Theor. Appl. Genet. 107:332-339. 